Original Research Paper

\title{
Physiological Active Substance Changes of Soybean Curd Residue Fermented by Preussia aemulans and its Bioactivity
}

\author{
${ }^{1}$ Yiting Li, ${ }^{2}$ Shili Meng, ${ }^{2}$ Min Shi and ${ }^{2}$ Zhenya Zhang \\ ${ }^{I}$ Key Laboratory of Food Nutrition and Safety, College of Food Engineering and Biotechnology, \\ Tianjin University of Science and Technology, Ministry of Education, Tianjin 300457, China \\ ${ }^{2}$ Graduate School of Life and Environmental Science, \\ University of Tsukuba, 1-1-1 Tennodai, Tsukuba, Ibaraki 305-8572, Japan
}

\author{
Article history \\ Received: 19-10-2015 \\ Revised: $28-10-2015$ \\ Accepted: 28-11-2015 \\ Corresponding Author: \\ Yiting Li \\ Key Laboratory of Food \\ Nutrition and Safety, College of \\ Food Engineering and \\ Biotechnology, Tianjin \\ University of Science and \\ Technology, Ministry of \\ Education, Tianjin 300457, \\ China \\ Tel/Fax: +86-22-6091-2431 \\ Email: liyitingyoyo@hotmail.com
}

\begin{abstract}
A new species of fungus Preussia aemulans isolated from the Cordyceps sinensis fruiting body was cultured by soybean curd residue using solid-state fermentation method. The content of polysaccharide, amino acid, protein, phenolics and nucleoside were massively improved under the optimum conditions, including $10 \%$ adding dosage of glucose, $3 \%$ adding dosage of beef extract, 15 days of fermentation time. The crude Polysaccharide (CPS) fraction indicated significant immunomodulatory activity on macrophage RAW 264.7 cells and the Ethyl Acetate Extract (EAE) fraction revealed the moderate anti-proliferation ability on human colon cancer cell DLD-1 at high concentration. Both of CPS and EAE showed excellent antioxidant activities properties. The results were demonstrated that the fermented Soybean Curd Residue (SCR) could be utilized as nontoxic, safe and functional food, food additive and feed.
\end{abstract}

Keywords: Soybean Curd Residue, Preussia aemulans, Antioxidative Property, Immunomodulatory Activity, Anti-Tumor Activity

\section{Introduction}

Soybean Curd Residue (SCR), a by-product of tofu, soymilk or soy protein processing, is discharged as an agro-industrial waste and has caused severe environmental pollution (Mizumoto et al., 2006). In fact, dried SCR is quite rich in proteins (20-30\%), lipids (9$20 \%$ ), carbohydrates (more than 50\%) and fibres (9$20 \%$ ) (Surel and Couplet, 2005). Several studies have recently investigated SCR as a nitrogen source was used for the solid-state fermentation of a microorganism (Li et al., 2014) and to produce polysaccharide by Flammulina velutipes and Ganoderma lucidum (Shi et al., 2012; 2013).

Cordyceps sinensis (C. sinensis) (Berk.) Sacc is a parasitic fungus used to treat multitude of ailments, promote longevity, increase athletic power and improve quality of life. Recent studies have demonstrated its multiple pharmacological actions in potentiating the immune system (Meng et al., 2013), the antitumor activity (Li et al., 2006) and the anti-oxidation activity (Wang et al., 2015). Furthermore, according to previous researches, 572 species fungi (Preussia intermedia, Penicillium boreae etc.) were isolated from different parts (stromata, sclerotia and external mycelial cortices) of natural C. sinensis fruiting body and all of the isolated fungus had the similar metabolites and exhibited the similar pharmacological activities as C. sinensis (Zhang et al., 2010). Previous studies have revealed that the Cordyceps and its anamorph possessed variety of biologically active substances, such as adenosine and ergosterol, especially polysaccharides which exhibited antioxidative and antitumor activities and regulation of immune functions (Paterson, 2008).

Many studies have shown that Reactive Oxygen Species (ROS) may be responsible for or contribute to human diseases (Wu and Hansen, 2008). Antioxidants, such as polysaccharide, phenolic compounds, flavonoids compounds can scavenge free radicals and protect against diseases. Macrophages have a significant role in host defense mechanisms. Phagocytic activity produces ROS and Nitric Oxide (NO) in response to stimulation from a variety of agents and it can inhibit the growth of a wide variety of tumor cells and micro-organisms. Moreover, the immunomodulatory activity not only involves macrophage activation but also proliferation and differentiation of these cells (Schepetkin and Quinn, 2006). Cancer is one of the most prevalent diseases 
worldwide. Papers reported that high ROS levels could induce apoptosis and necrosis, which were both evidenced to be related to cancer and neurodegenerative disorders (Kregel and Zhang, 2007). Therefore, antioxidants, which could prevent the high level of ROS, were considered as anti-cancer agents.

Up to now, the new species fungus Preussia aemulans ( $P$. aemulans) which isolated from $C$. sinensis fruiting body has not been reported in any other research. Therefore, the purpose of this study was investigated the physiological active substance content and the bioactivity of the $P$. aemulans fungus using SCR by solid-state fermentation.

\section{Materials and Methods}

\section{Isolation and Cultivation of Preussia Aemulans}

The fruiting body of $C$. sinensis was purchased from Qinghai, China and the isolated $P$. aemulans mycelium (SIID11759-01) was identified by Techno Suruga Laboratory Co., Ltd, Japan. The stroma of the C. sinensis fruiting body was sterilized with ethanol three times, airdried, cut into small segments and transferred to a slant tube fermentor to incubate for 7 days at room temperature.
A white mycelium appeared on the surface during slant fermentation. Then, this mycelium was transferred to agar medium, that contained (per liter): $20 \mathrm{~g}$ of sucrose, $10 \mathrm{~g}$ of peptone, $20 \mathrm{~g}$ of agar powder, $1.5 \mathrm{~g}$ of $\mathrm{MgSO}_{4}$ and $3 \mathrm{~g}$ of $\mathrm{KH}_{2} \mathrm{PO}_{4}$. After 7 days incubation, the mycelium was transferred into the liquid medium, that contained (per liter): $20 \mathrm{~g}$ of sucrose, $10 \mathrm{~g}$ of peptone, 4 $\mathrm{g}$ of potato powder, $1.5 \mathrm{~g}$ of $\mathrm{MgSO}_{4}$ and $3 \mathrm{~g}$ of $\mathrm{KH}_{2} \mathrm{PO}_{4}$. The mycelium was incubated in a $200 \mathrm{~mL}$ of flask with $100 \mathrm{~mL}$ of PDA liquid medium and the mixture was stationary cultured for 7 days. After stationary culture, the $P$. aemulans mycelium was inoculated onto SCR following the orthogonal experiment design which revealed in our previous research (Li et al., 2015) and the optimum fermentation conditions were: $10 \%(\mathrm{w} / \mathrm{v})$ of glucose, $3 \%(\mathrm{w} / \mathrm{v})$ of beef extract and 15 days of fermentation time.

\section{Separation of the Fermented SCR}

As shown in Fig. 1, the fermented SCR was separated into five fractions, Petroleum Ether Extract (PEE), Ethyl Acetate Extract (EAE), 1-Butanol Extract (BE), Water Extract (WE) and Crude Polysaccharide (CPS), respectively. After the separation, each fraction was collected and lyophilized for the further analysis.

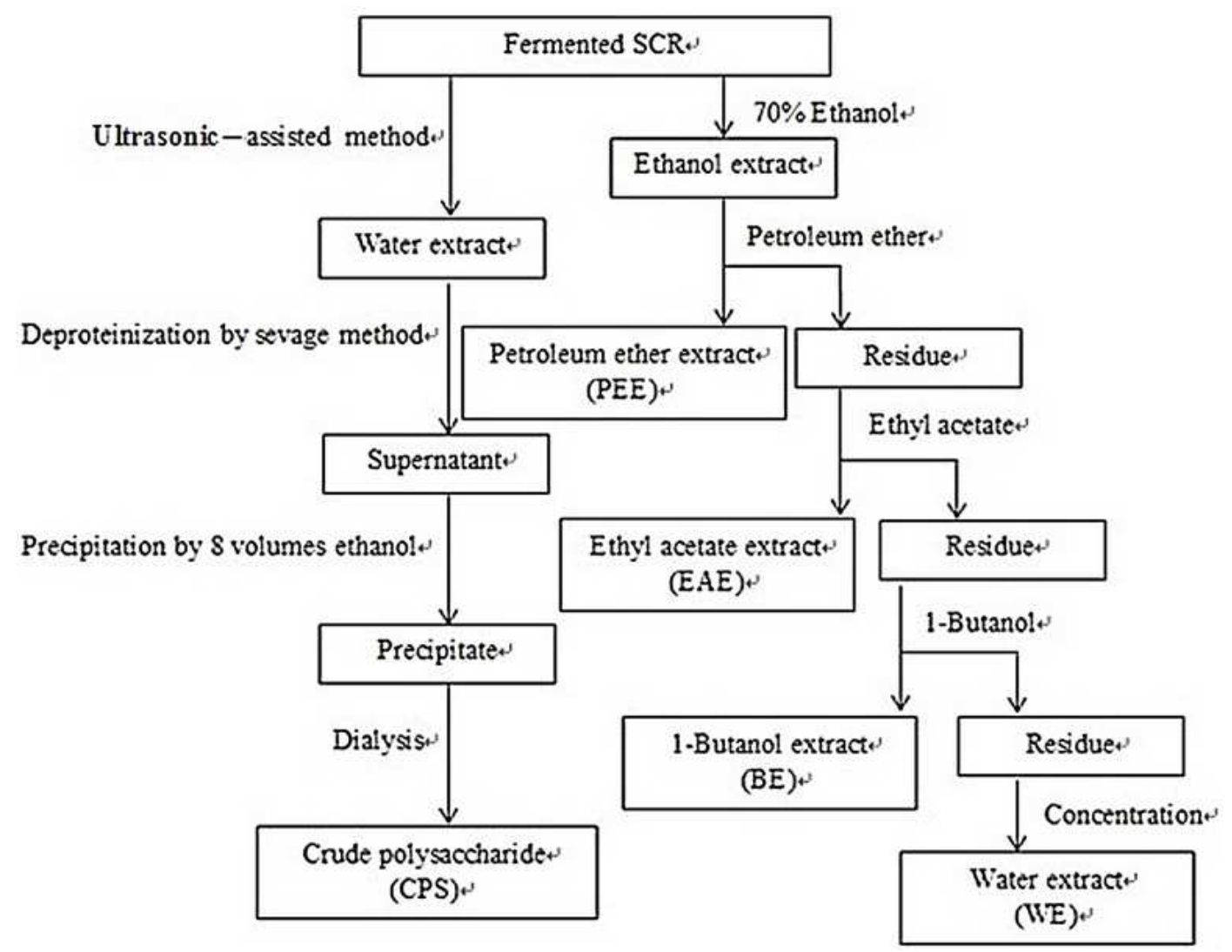

Fig. 1. Extraction flow chart of fermented SCR 


\section{Determination of Polysaccharide Content}

The color reaction was initiated by mixing $1 \mathrm{~mL}$ of sample with $0.5 \mathrm{~mL}$ of phenol solution and $2.5 \mathrm{~mL}$ of $95 \%$ sulfuric acid and the mixture was kept in a boiling water bath for 15 min (Masuko et al., 2005). After it cooling to room temperature, the O.D. was determined at $490 \mathrm{~nm}$ and the polysaccharide content was calculated with D-glucose as the standard.

\section{Determination of Total Phenolics Content}

The total phenolics content was estimated by the Folin-Ciocalteu colorimetric method with some modifications ( $\mathrm{Hu}$ et al., 2009). The sample $(0.5 \mathrm{~mL})$ was mixed with $0.5 \mathrm{~mL}$ of the Folin-Ciocalteu reagent. Three minutes later, $0.5 \mathrm{~mL}$ of $20 \% \mathrm{Na}_{2} \mathrm{CO}_{3}$ was added and the mixture was made up to $5 \mathrm{~mL}$ with distilled water. After being kept in dark for $90 \mathrm{~min}$, the O.D. of the mixture was read at $725 \mathrm{~nm}$. The total phenolics content was calculated with gallic acid as the standard and expressed as milligram gallic acid equivalent (mg GAE/g extract).

\section{Determination of Total Free Amino Acid Content}

The free amino acid content was determined using a previously reported method (Shi et al., 2011). The fermented SCR powder was extracted by $80 \%$ ethanol in $80^{\circ} \mathrm{C}$ water bath for $20 \mathrm{~min}$ and the step was repeated twice. Then all of the collected supernatant was centrifuged and filtered. The supernatant was evaporated to dryness and dissolved with distilled water. The solution was mixed with TCA solution at the ratio of $4: 1$ and placing at $4{ }^{\circ} \mathrm{C}$ for $10 \mathrm{~min}$. The $\mathrm{pH}$ was adjusted with $\mathrm{NaOH}$ and $\mathrm{HCl}$ at the range of 2-3. Finally the supernatant was filtered by $0.45 \mu \mathrm{m}$ filter and assessed by an auto amino acid analyzer (JLC 500/V2, Jeol Ltd., Tokyo, Japan) in Chemical Analysis Center (university of Tsukuba).

\section{Determination of Protein Content}

The protein content was determined using the Protein Quantification Kit-Rapid (Wako Pure Chemical, Osaka) (Shi et al., 2011). Briefly, $6 \mu \mathrm{L}$ of fermented broth and $300 \mu \mathrm{L}$ of Coomassie Brilliant Blue (CBB) were added into a 96-well plate separately, then the O.D. of the mixture was read at $595 \mathrm{~nm}$ and the protein content was calculated using a Bovine Serum Albumin (BSA) solution as the standard. The results were expressed as milligram of protein per gram of the fermented SCR.

\section{Determination of Nucleosides Content}

The fermented SCR was extracted with deionized water by ultrasonic-assisted extract method for $1 \mathrm{~h}(50$ w). Then, the supernatant was collected and filtered $(0.45 \mu \mathrm{m})$ for HPLC determination. The samples were analyzed by the HPLC with Capcell-Pak $\mathrm{C}_{18}$ column (4.6 $\mathrm{mm}$ I.D. $\times 150 \mathrm{~mm}$, particle size of $5 \mu \mathrm{m})$ in a flow rate of $1.0 \mathrm{~mL} / \mathrm{min}$, the column temperature was set at $30^{\circ} \mathrm{C}$ and the UV detection was operated at $260 \mathrm{~nm}$. The mobile phase was a mixture of acetonitrile and water. For the determination of adenosine, guanosine and thymidine, the mobile phase was a mixture of acetonitrile-water $(5: 95, \mathrm{v} / \mathrm{v})$. For the determination of uridine, the mobile phase was a mixture of acetonitrilewater $(2: 98, \mathrm{v} / \mathrm{v})$ and the determination of cytidine, $0.01 \mathrm{M} \mathrm{KH}_{2} \mathrm{PO}_{4}$ was used as the mobile phase and the concentration of adenosine, guanosine, uridine, thymidine and cytidine was calculated by comparing peak areas with appropriate standards.

\section{Determination of SOD-Like Activity}

The levels of SOD-like activity in the extracts were measured using the SOD Assay Kit-WST according to the technical manual provided by Dojindo Molecular Technologies, Inc. Briefly, in a 96-well plate, $20 \mu \mathrm{L}$ of sample solution was added to each sample and blank 2 well and $20 \mu \mathrm{L}$ of double distilled water was added to each blank 1 and blank 3 well. Then $200 \mu \mathrm{L}$ of WST working solution was added to each well. After mixing, $20 \mu \mathrm{L}$ of dilution buffer was added to each blank 2 and blank 3 well and $20 \mu \mathrm{L}$ of enzyme working solution was added to each sample and blank 1 well. The plate was incubated at $37^{\circ} \mathrm{C}$ for $20 \mathrm{~min}$ and the Optical Density (OD) was determined at $450 \mathrm{~nm}$ using a microplate reader (BIO-RAD Model 550, California, USA). The SOD-like activity was calculated by the following Equation 1:

$$
\begin{aligned}
& \text { SOD activity (inhibition rate } \%) \\
& =\left\{\left[\begin{array}{l}
\left(\mathrm{A}_{\text {blank1 }}-\mathrm{A}_{\text {blank3 }}\right) \\
-\left(\mathrm{A}_{\text {sample }}-\mathrm{A}_{\text {blank2 }}\right)
\end{array}\right] /\left(\mathrm{A}_{\text {blank1 }}-\mathrm{A}_{\text {blank3 }}\right)\right\} \times 100 \%
\end{aligned}
$$

where, $A_{\text {blank } 1,} A_{\text {blank2 }}, A_{\text {blank3 }}$ and $A_{\text {sample }}$ were the absorbance of blank 1, blank 2, blank 3 and the sample, respectively. 1 Unit of SOD activity was defined as the amount of enzyme having a $50 \%$ inhibitory effect on WST-1.

\section{DPPH Radical-Scavenging Properties}

The DPPH radical-scavenging property was measured according to previous report (Nakajima et al., 2007). $0.5 \mathrm{~mL}$ of various concentrations of samples were mixed with $2 \mathrm{~mL}\left(25 \mu \mathrm{g} \mathrm{mL}{ }^{-1}\right)$ of a Methanol solution of DPPH. The mixture was shaked immediately after adding DPPH and then kept stand in the dark for $30 \mathrm{~min}$ at room temperature. The absorbance was measured at $517 \mathrm{~nm}$. Ascorbic Acid was used as the positive control. DPPH free radical-scavenging property was calculated according to the following Equation 2: 
DPPH radical - scavenging activity $(\%)$

$=\left[\mathrm{A}_{0}-\mathrm{A}_{1} / \mathrm{A}_{0}\right] \times 100 \%$

where, $\mathrm{A}_{0}$ represented the absorbance without samples and $A_{1}$ was the absorbance in the presence of samples.

\section{Scavenging Ability on Hydroxyl Radicals}

The HO• scavenging activity was measured according to previous report with some modifications (Liu et al., 2010). The reaction mixture $(250 \mu \mathrm{L})$ contained $50 \mu \mathrm{L}$ of $\mathrm{FeSO}_{4}(1.5 \mathrm{mM}), 35 \mu \mathrm{L}$ of $\mathrm{H}_{2} \mathrm{O}_{2}$ (6 mM), $15 \mu \mathrm{L}$ of sodium salicylate $(20 \mathrm{mM})$ and 100 $\mu \mathrm{L}$ of different concentrations of samples. Ascorbic Acid was used as the positive control. After reaction for $1 \mathrm{~h}$ at $37^{\circ} \mathrm{C}$, the absorbance of the hydroxylated salicylate mixture was determined at $560 \mathrm{~nm}$, by a microplate spectrophotometer (BIO-RAD Model 550, USA). The percentage scavenging effect was calculated as Equation 3:

Scavenging activity $(\%)=\left[1-\left(A_{1}-A 2\right) / A_{0}\right] \times 100 \%$

where, $\mathrm{A}_{0}$ represented the absorbance of the solvent control, $A_{1}$ was the absorbance of sample or ascorbic acid and $\mathrm{A}_{2}$ was absorbance of the reagent blank without sodium salicylate.

\section{FT-IR Spectrum of CPS}

The Infrared (IR) spectrum of the CPS was determined using a Fourier transform infrared spectrophotometer (Herscel FT/IR-300, Jasco, Japan). The CPS was ground with spectroscopic-grade potassium bromide $(\mathrm{KBr})$ powder and then pressed into $1 \mathrm{~mm}$ pellets for IR measurement in the $4000-400 \mathrm{~cm}^{-1}$ frequency range (Chen et al., 2011).

\section{Cell Culture}

The murine macrophage cell line, RAW 264.7 was obtained from Riken Cell Bank (Tsukuba, Japan) and maintained in MEM medium containing $10 \%$ fetal bovine serum, $100 \mathrm{U} \mathrm{mL}^{-1}$ penicillin and $100 \mu \mathrm{g} \mathrm{mL}^{-1}$ of streptomycin at $37^{\circ} \mathrm{C}$ in a humidified $5 \% \quad \mathrm{CO}_{2}$ atmosphere (ESPEC $\mathrm{CO}_{2}$ Incubator). Cells were cultured for 2-3 days to reach the logarithmic phase and used for further analysis.

DLD-1 human colon cancer cell line was obtained from the Cell Resource Center for Biomedical Research, Aging and Cancer, Tohoku University (Japan). It was grown in RPMI1640 medium containing $10 \%$ Fetal Bovine Serum (FBS) and $1 \%$ penicillin/streptomycin. Culture was maintained at $37^{\circ} \mathrm{C}$ in a humidified $5 \% \mathrm{CO}_{2}$ atmosphere $\left(\right.$ ESPEC $\mathrm{CO}_{2}$ Incubator). Cells were cultured for 2-3 days to reach the logarithmic phase and used for further analysis.

\section{The Effect of CPS on Macrophage Cell Proliferation}

The effect of CPS on the proliferation of RAW 264.7 cells was estimated using the Cell Counting Kit-8 (CCK8, Dojindo Molecular Technologies, Kumamoto, Japan). RAW 264.7 cells were cultured in a 96-well plate at a density of $5 \times 10^{4}$ cells $/ \mathrm{mL}$ at $37^{\circ} \mathrm{C}$ in a $5 \% \quad \mathrm{CO}_{2}$ atmosphere for $24 \mathrm{~h}$. Next the cells were incubated with various concentrations of $\mathrm{CPS}$ at $37^{\circ} \mathrm{C}$ for $24 \mathrm{~h}$. After incubation, $10 \mu \mathrm{L}$ of CCK-8 solution was added and incubated at $37^{\circ} \mathrm{C}$ for $4 \mathrm{~h}$. The cell viability was determined by the O.D. at the wavelength of $450 \mathrm{~nm}$ with a microplate reader (BIO-RAD Model 550, USA). The data were expressed as percentages of the control.

\section{Measurement of the Production of the Nitric Oxide}

The macrophage cells $\left(1 \times 10^{5}\right.$ cells $\left./ \mathrm{mL}\right)$ were dispensed into a 96-well plate for $24 \mathrm{~h}$. Next the cells were stimulated with LPS $\left(1 \mu \mathrm{g} \mathrm{mL}{ }^{-1}\right)$ and various concentrations of CPS for $24 \mathrm{~h}$. After incubation, $50 \mu \mathrm{L}$ of the culture supernatants were mixed with $50 \mu \mathrm{L}$ of Griess reagent in a 96-well plate and incubated at $25^{\circ} \mathrm{C}$ for $10 \mathrm{~min}$. The absorbance at $570 \mathrm{~nm}$ was measured on a microplate reader. The nitrite accumulation was measured to assess the NO production in the RAW 264.7 cells. $\mathrm{NaNO}_{2}$ was used as standard to calculate the nitrite concentrations.

\section{Inhibitory Effect of EAE on DLD-1 Cells}

DLD-1 cells were grown in RPMI-1640 medium at $37^{\circ} \mathrm{C}$ in a $5 \% \mathrm{CO}_{2}$ atmosphere to logarithmic phase. Cells were harvested and an aliquot $(100 \mu \mathrm{L})$ of DLD1 cells suspension $\left(5 \times 10^{4}\right.$ cells $\left./ \mathrm{mL}\right)$ were dispensed into a 96 -well plate and pre-incubated at $37^{\circ} \mathrm{C}$ in a $5 \%$ $\mathrm{CO}_{2}$ atmosphere for $24 \mathrm{~h}$. Then cells were exposed to various concentrations of extracts $(5,10,20$ and $40 \mu \mathrm{g} \mathrm{mL}^{-1}$ ) for $24 \mathrm{~h}$. After EAE fraction exposure, $10 \mu \mathrm{L}$ of CCK-8 solution was added and incubated at $37^{\circ} \mathrm{C}$ for $4 \mathrm{~h}$. Cell numbers were quantitated by reading the $\mathrm{OD}$ at $450 \mathrm{~nm}$ with a microplate reader (BIO-RAD Model 550, California, USA).

\section{Statistical Analysis}

Statistical analyses were done using the DPS statistical analysis (DPS, version 13.5) software package (Hangzhou city, Zhejiang province, China). The results were presented as means of three determinations \pm SD (standard deviation).

\section{Results}

Physiological Active Substance Content in Fermented and Unfermented SCR

The results of physiological active substance content in fermented and unfermented SCR were shown in Table 1. 
Table 1. Physiological active substances contents of unfermented and fermented SCR

\begin{tabular}{|c|c|c|c|}
\hline \multicolumn{2}{|l|}{ Physiological active substances } & \multirow{2}{*}{$\begin{array}{l}\text { Unfermented SCR } \\
12.21 \pm 0.56\end{array}$} & \multirow{2}{*}{$\begin{array}{l}\text { Fermented SCR } \\
48.44 \pm 1.29\end{array}$} \\
\hline Phenolics (mg GAE/g dry matter) & & & \\
\hline Protein (mg/g dry matter) & & $217.56 \pm 14.7$ & $192.20 \pm 10.28$ \\
\hline \multirow[t]{4}{*}{ Nucleoside (mg/100 g dry matter) } & Guanosine & $26.21 \pm 0.37$ & $83.51 \pm 4.62$ \\
\hline & Uridine & $250.11 \pm 14.28$ & $369.79 \pm 12.14$ \\
\hline & Thymidine & $0.28 \pm 0.01$ & $9.51 \pm 0.56$ \\
\hline & Cytidine & $14.18 \pm 0.61$ & $68.56 \pm 5.57$ \\
\hline Amino acid ( $\mu \mathrm{mol} / \mathrm{g}$ dry matter $)$ & Totoal amino acid & $19.15 \pm 0.76$ & $189.14 \pm 4.32$ \\
\hline \multirow[t]{9}{*}{ Essential amino acid } & Threonine & $0.39 \pm 0.01$ & $3.07 \pm 0.10$ \\
\hline & Valine & $0.95 \pm 0.01$ & $8.66 \pm 0.23$ \\
\hline & Methionine & $0.14 \pm 0.01$ & $1.04 \pm 0.06$ \\
\hline & Leucine & $0.89 \pm 0.03$ & $8.16 \pm 0.12$ \\
\hline & Tyrosine & $0.41 \pm 0.01$ & $6.86 \pm 0.18$ \\
\hline & Lysine & $0.14 \pm 0.02$ & $2.85 \pm 0.16$ \\
\hline & Isoleucine & $0.43 \pm 0.04$ & $5.32 \pm 0.24$ \\
\hline & Histidine & $0.09 \pm 0.01$ & $0.65 \pm 0.01$ \\
\hline & Phenylalanine & $0.92 \pm 0.04$ & $11.91 \pm 0.31$ \\
\hline \multirow[t]{9}{*}{ Nonessential amino acid } & Alanine & $2.53 \pm 0.13$ & $8.34 \pm 0.28$ \\
\hline & Cysteine & ND & $0.27 \pm 0.01$ \\
\hline & Asparagines & $1.24 \pm 0.09$ & $3.41 \pm 0.11$ \\
\hline & Glutamic acid & $0.81 \pm 0.07$ & $13.80 \pm 0.72$ \\
\hline & Glycine & $0.38 \pm 0.01$ & $2.85 \pm 0.25$ \\
\hline & Arginine & $0.18 \pm 0.01$ & $1.14 \pm 0.06$ \\
\hline & Serine & $0.46 \pm 0.01$ & $1.85 \pm 0.07$ \\
\hline & Proline & $0.53 \pm 0.02$ & $8.46 \pm 0.48$ \\
\hline & $\gamma$-Aminobutyric acid & $0.63 \pm 0.04$ & $2.55 \pm 0.13$ \\
\hline
\end{tabular}

The polysaccharide content of the fermented SCR was increased from $12.91 \pm 0.39 \mathrm{mg} \mathrm{g}^{-1}$ dry matter to $43.49 \pm 1.48 \mathrm{mg} \mathrm{g}^{-1}$ dry matter. The total phenolics content of fermented SCR was increased by 4 -fold after fermentation, from $14.16 \pm 0.53$ to $89.83 \pm 4.26 \mathrm{mg}$ GAE $\mathrm{g}^{-1}$ dry matter. For the protein content, the fermented SCR was $192.20 \pm 10.28 \mathrm{mg} \mathrm{g}^{-1}$ dry matter. In contrast to the unfermented SCR, the total free amino acid content of fermented SCR was $189.14 \pm 4.32 \mu \mathrm{mol} \mathrm{g}{ }^{-1}$, exhibiting an increase of 10 -fold. For the essential amino acid, all of the amino acids of fermented SCR were increased significantly during fermentation time. Lysine was enhanced an increase of 20 -fold which was the maximum increase of these essential amino acids. For the nonessential amino acid, all of the amino acids were increased. Especially, the glutamic acid was increased the most remarkably (17-fold). Cysteine, the one species of nonessential amino acid does not exist in unfermented $\mathrm{SCR}$ and it reached to $0.27 \pm 0.01 \mu \mathrm{mol} \mathrm{g} \mathrm{g}^{-1}$. $\Gamma$ Aminobutyric acid was increased 4-fold. Compared with the unfermented SCR, guanosine, uridine, thymidine and cytidine were improved by 3 -fold, 1.5-fold, 34-fold and 5-fold, respectively.

\section{Antioxidant Properties}

For the results of DPPH radical-scavenging activities, the $\mathrm{EC}_{50}$ of PEE, EAE, BE, WE and CPS were shown in Table 2. It was indicated that all of the isolated fractions and ascorbic acid (positive control) were found to be effective scavenger against DPPH radical. Moreover, the CPS indicated the most excellent antioxidative property with $0.48 \mathrm{mg} \mathrm{mL}^{-1}$ of the $\mathrm{EC}_{50}$.

All of the isolated fractions and ascorbic acid (positive control) exhibited remarkable hydroxyl radical removal activity (Table 2). Moreover, among the isolated fractions, CPS indicated the highest radical scavenge activity with $0.32 \mathrm{mg} \mathrm{mL}^{-1}$ of the $\mathrm{EC}_{50}$ and EAE $(0.32$ $\mathrm{mg} \mathrm{mL}^{-1}$ of $\mathrm{EC}_{50}$ ) showed the similar property as CPS.

\section{Components Analysis of CPS and EAE}

As shown in Table 3, the polysaccharide, phenolics, protein content and SOD-like activity of CPS and EAE were determined. The polysaccharide content of CPS was $602.42 \pm 4.35 \mathrm{mg} \mathrm{g}^{-1}$ extract, which was much higher than other compounds. The SOD-like activity of EAE was $74.63 \pm 0.72 \mathrm{U} \mathrm{mg}^{-1}$.

\section{FT-IR Spectrum of CPS}

As shown in Fig. 2, the largest absorption band at 3380 $\mathrm{cm}^{-1}$ is assigned to the hydroxyl group and the small band at $2921 \mathrm{~cm}^{-1}$ are due to $\mathrm{C}-\mathrm{H}$-stretching vibration. The absorption bands at 1640 and $1542 \mathrm{~cm}^{-1}$ are attributed to the stretching vibration of the carbonyl bond, $\mathrm{C}-\mathrm{O}$ of the amide group and the bending vibration of the $\mathrm{N}-\mathrm{H}$ bond in peptides or proteins (Leung et al., 2009). The 
stretching peak at 1089 and $1026 \mathrm{~cm}^{-1}$ are suggestive of a C-O bond (Yan et al., 2010). Moreover, characteristic absorptions at $889 \mathrm{~cm}^{-1}$ in the FT-IR spectrum indicated a $\beta$-anomeric configuration in CPS (Pan and Mei, 2010; Kozarski et al., 2012).

\section{Effect of CPS on Macrophages Proliferation and Nitric Oxide Production}

It was interesting to note that in the range of 5-20 $\mu \mathrm{g} \quad \mathrm{mL}^{-1}$, CPS stimulated RAW 264.7 cells proliferation in a dose-dependent manner (Fig. 3). At the concentration of $20 \mu \mathrm{g} \mathrm{mL} \mathrm{m}^{-1}$, the stimulation effect reached maximum, which was $169.55 \%$. Though the concentration increased to $40 \mu \mathrm{g} \mathrm{mL}$, the cells survival rate decreased and the RAW 264.7 cells survival rate $(160.55 \%)$ was still much higher than control. The positive control, LPS $\left(1 \mu \mathrm{g} \mathrm{mL}{ }^{-1}\right)$ was showed the higher stimulation effect with the stimulation effect of $196.06 \%$.

As shown in Fig. 3, the NO production indicated that incubation with CPS stimulated RAW 264.7 cells to produce $\mathrm{NO}$ in a dose-dependent manner at 5-20 $\mu \mathrm{g}$ $\mathrm{mL}^{-1}$ and the NO production was decreased at $40 \mu \mathrm{g}$ $\mathrm{mL}^{-1}$, with $12.24 \mu \mathrm{M}$. At the concentration of $20 \mu \mathrm{g}$ $\mathrm{mL}^{-1}$, the maximum $\mathrm{NO}$ production was observed $(14.27 \mu \mathrm{M})$, in contrast with the control $(4.63 \mu \mathrm{M})$ $(\mathrm{p}<0.01)$. The positive control, LPS $\left(1 \mu \mathrm{g} \mathrm{mL} \mathrm{m}^{-1}\right)$ was $20.52 \mu \mathrm{M}$ of NO production.

\section{Inhibitory Effect of EAE on DLD-1 Cells}

EAE fractions were used for the anti-proliferation on DLD-1 cells (Fig. 4). In this experiment various concentrations of extracts $\left(5,10,20\right.$ and $\left.40 \mu \mathrm{g} \mathrm{mL}^{-1}\right)$ were used. The results showed that, the EAE revealed the moderate anti-proliferation ability on human colon cancer cell DLD-1 and the cell survival rates were decreased with increase of the concentration of extracts. While the treatment at the concentration of $40 \mu \mathrm{g} \mathrm{mL} \mathrm{m}^{-1}$, EAE revealed the strongest inhibitory effect on DLD-1 cells proliferation, which was $19.21 \%$.

Table 2. EC50 of various antioxidative activities

\begin{tabular}{|c|c|c|c|c|c|c|}
\hline & \multicolumn{6}{|c|}{$\mathrm{EC}_{50} \mathrm{mg} / \mathrm{mL}$} \\
\hline & PEE & EAE & $\mathrm{BE}$ & WE & CPS & $\begin{array}{l}\text { Ascorbic } \\
\text { acid }\end{array}$ \\
\hline $\begin{array}{l}\text { DPPH radical } \\
\text {-scavenging activities }\end{array}$ & 11.73 & 1.44 & 1.83 & 1.69 & 0.48 & 0.04 \\
\hline $\begin{array}{l}\text { Scavenging activities } \\
\text { of hydroxyl radical }\end{array}$ & 1.20 & 0.33 & 0.46 & 0.61 & 0.32 & 0.05 \\
\hline
\end{tabular}

Table 3. Compounds analysis of CPS and EAE

\begin{tabular}{lll}
\hline & CPS & EAE \\
\hline Polysaccharide content (mg/g extract) & $602.42 \pm 4.35$ & - \\
Phenolics content (mg GAE/g extract) & $26.71 \pm 0.25$ & $42.52 \pm 1.50$ \\
Protein content (mg/g extract) & $33.04 \pm 1.46$ & - \\
SOD-like activity (U/mg) & $8.06 \pm 0.18$ & $74.63 \pm 0.72$ \\
\hline
\end{tabular}

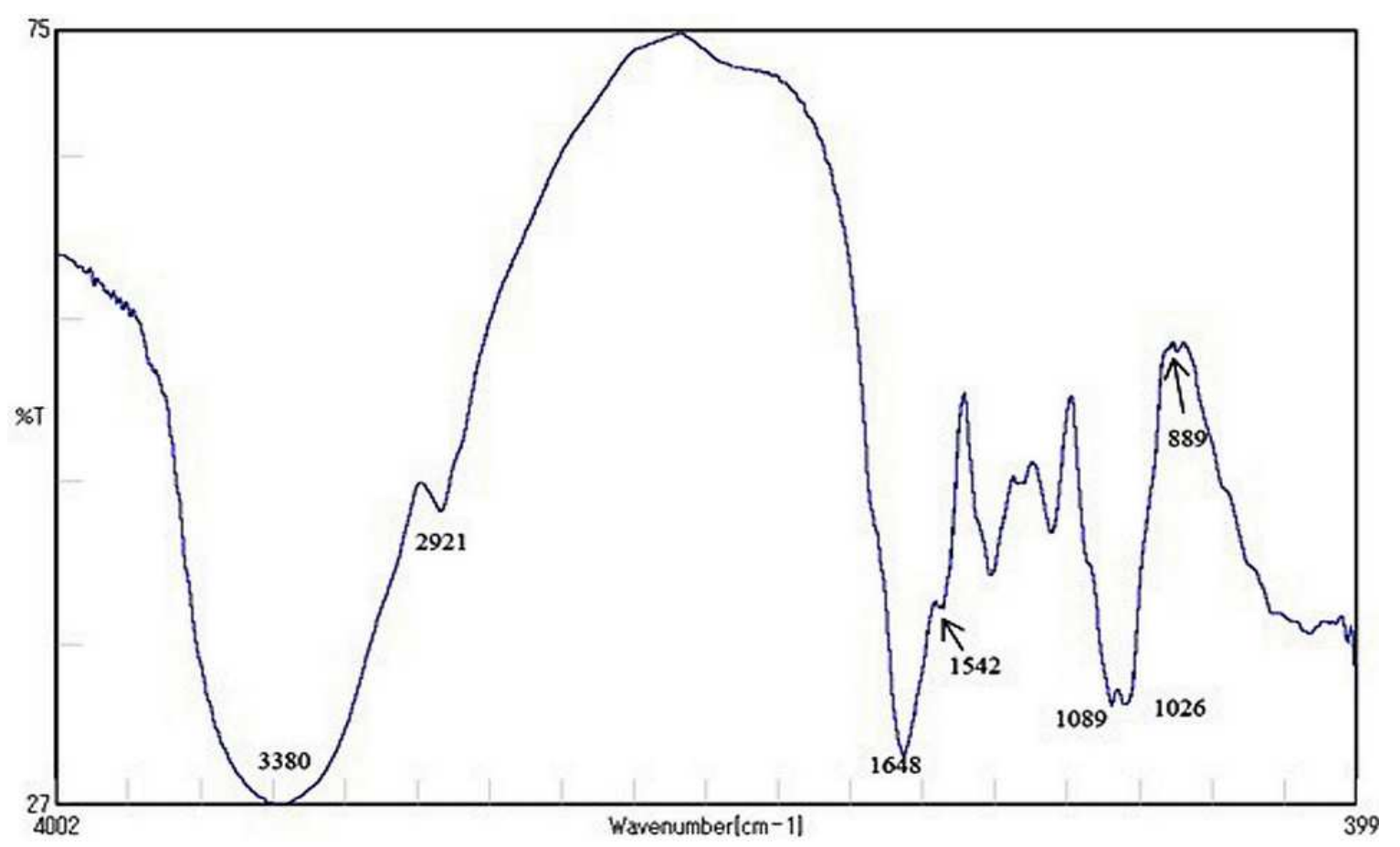

Fig. 2. IR spectrum of CPS 


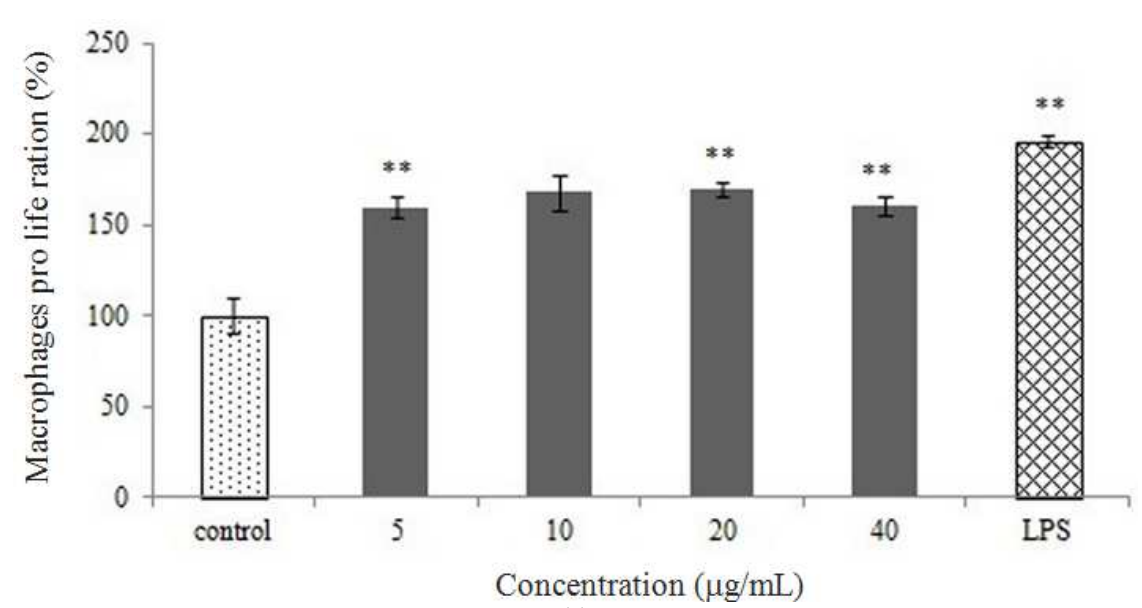

(a)

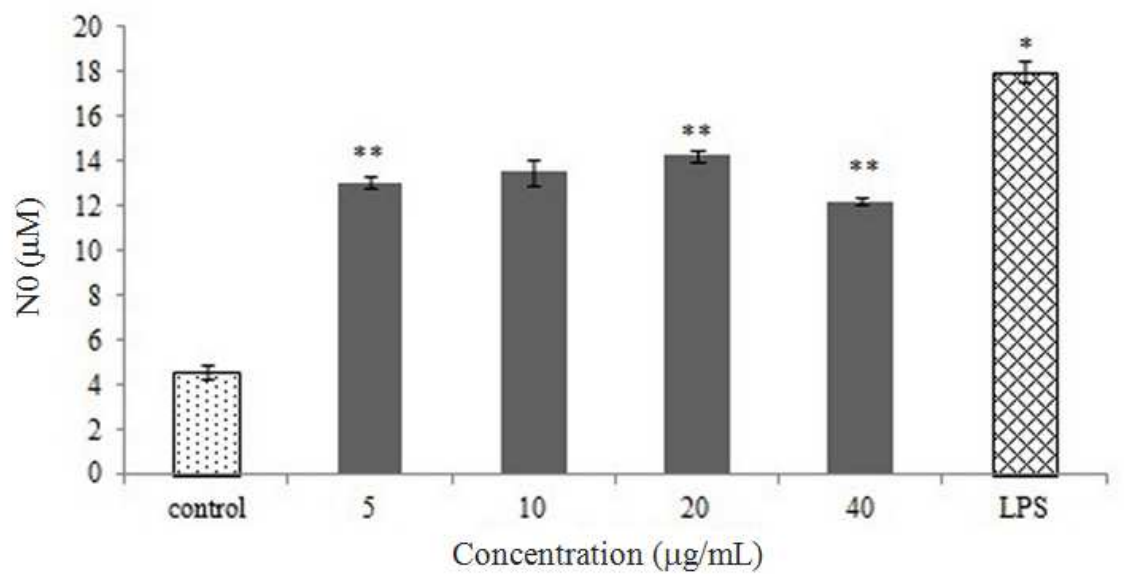

(b)

Fig. 3. Effect of CPS on macrophage RAW 264.7, (A) Cells proliferation; (B) NO production LPS was positive control, at a concentration of $1 \mu \mathrm{g} \mathrm{mL}^{-1}$. Data are expressed as means \pm S.D. of three independent experiments $\left({ }^{*} p<0.05\right.$ and ${ }^{* *} p<0.01$ in comparison with control)

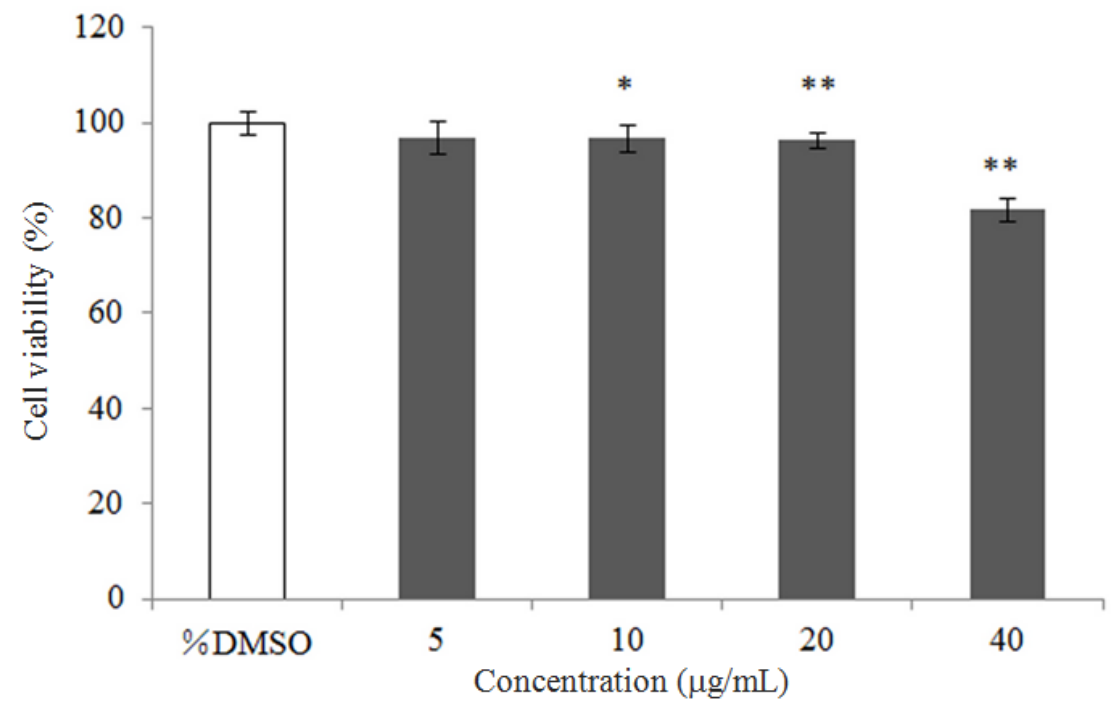

Fig. 4. Anti-proliferative effect of EAE on DLD-1 cells data are expressed as means \pm S.D. of three independent experiments $\left({ }^{*} \mathrm{p}<0.05\right.$ and $* * \mathrm{p}<0.01$ in comparison with control) 


\section{Discussion}

After fermentation, the polysaccharide, total phenolics, protein, amino acids and nucleosides contents were increased significantly. Polysaccharides have been identified as the major active components of $C$. sinensis with a wide range of bioactivities including immunomodulation, antitumour, antioxidation and hypoglycemic effects (Yan et al., 2014). Mushrooms could accumulate a variety of secondary metabolites, such as phenolic compounds, polyketides, terpenes and steroids (Cheung et al., 2003). Among of them, phenolics are suggested to be the major bioactive compounds for health benefits and found to be associated with the inhibition of atherosclerosis and cancer (Puttaraju et al., 2006; Klimczak et al., 2007). In this study, the protein content was decreased after fermentation, however the protein of SCR is hydrolysed to produce the peptide which takes on good solubility, the low viscosity (Shi et al., 2011). Thus, it is assimilated easily in vivo digestion to be suitable for children and old people. In free amino acids, lysine is an important essential amino acid for people and is beneficial for the physical growth and intelligence of children (Shi et al., 2013). Glutamic acid could exhibit protective effects on the heart muscle in human with heart disease. For $\gamma$-Aminobutyric acid, a non-protein amino acid that is widely distributed in nature from microorganisms to plants and animals ( $\mathrm{Li}$ et al., 2010) and it acts as the major inhibitory neurotransmitter in the mammalian central nervous system. In addition, $\gamma$ Aminobutyric acid also has hypotensive, tranquilizing and diuretic effects and can prevent diabetes (Wong et al., 2003). For Nucleosides, guanosine has many trophic effects in the central nervous system, including the stimulation of neurotrophic factor synthesis and release by astrocytes, which protect neurons against excitotoxic death (DiIorio et al., 2004). Uridine, is an essential component of RNA synthesis and plays an important role in the synthesis of glycogen (Yamamoto et al., 2011). In humans, uridine is administered to reduce the adverse effects of cancer chemotherapy, such as bone marrow and gastrointestinal toxicity (Yamamoto et al., 2002). Cytidine plays key roles in phosphoinositide signaling and the synthesis of lipids (Helmink and Friesen, 2004). In humans, thymine also plays an important role in the synthesis of DNA. In sum, the quantity and verities of active substances in SCR were raised obviously after fermentation. These indicated that the fermented SCR could be a potential and nutritious ecologic feed.

In the antioxidant assay, the EAE and CPS fractions showed the significant activity. According to the components analysis result, the polysaccharide content of CPS was much higher than other compounds. Polysaccharides have been demonstrated to play an important role as dietary free radical scavenger for the prevention of oxidative damage (Mohsen et al., 2009). Thus, the antioxidative property of CPS could be due to the high content of polysaccharide. SOD, which catalyzes the dismutation of the superoxide anion $\left(\mathrm{O}^{2-}\right)$ into hydrogen peroxide and molecular oxygen, is one of the most important enzymes in the front line of defense against oxidative stress (Jiang and Patrice, 2006). Therefore the strong antioxidative property of EAE could be related with the higher SOD-like activity.

For the bioactivity, the CPS fraction showed the significant immunomodulatory activity on macrophage RAW 264.7 cells and the EAE fraction revealed the moderate anti-proliferation ability on human colon cancer cell DLD-1 at high concentration. Immunomodulation is the most notable biological function of natural polysaccharides, which is associated with their putative role as biological response modifiers (Moradali et al., 2007) and previous literature has been reported that the $\beta$-glycosidic linkage was the essential structural feature for immunostimulatory and antitumoral effects (Hung et al., 2008; Song et al., 2012). Therefore, the immunomodulatory activity of CPS fraction may be connected with the $\beta$-anomeric configuration. Reactive Oxygen Species (ROSs) exist in various forms, including free radicals such as superoxide ions, hydroxyl radicals and peroxyl, as well as non-free-radical species such as hydrogen peroxide (Squadriato and Pryor, 1998; Waris and Ahsan, 2006) These ROSs could induce various diseases especially cancer. Thus, the moderate anti-proliferation ability of EAE fraction on human colon cancer cell DLD-1 could be related with its significant antioxidant activity.

\section{Conclusion}

The annual production of SCR reaches as high as 20 million tons in China, with 0.7-0.8 million tons in Japan. In Japan, most SCR is incinerated or landfilled directly and the disposal cost of SCR is 10,000-20,000 yen per ton. In this study, SCR was utilized as a media by the new species fungus of $P$. aemulans which isolated from $C$. sinensis fruiting body using solid-state fermentation method. This method not only reduced the environmental pollution, but also changed the byproduct to a useful material. The fermented SCR was rich in physiological active substances, low in cost and efficient in immunomodulation and anti-tumor effect, therefore the fermented SCR could be explored as ecological feed or functional food material in the further.

\section{Author's Contributions}

Yiting Li: Designed the research plan, participated in all experiments, aquisition of data, analyzed all the data and contributed to the writing of the manuscript. 
Shili Meng: Participated in Chemical characterization of CPS and EAE and analyzed all the data.

Min Shi: Participated in Cell experiment and contributed to the writing of the manuscript.

Zhenya Zhang: Provided technical guidance, coordinated the writing of the manuscript, designed the research plan and organized the study.

\section{Conflict of Interest}

The author declares that they have no conflict of interest.

\section{References}

Chen, Y., W.J. Mao, H.W. Tao, W.M. Zhu and X.H. Qi et al., 2011. Structural characterization and antioxidant properties of an exopolysaccharide produced by the mangrove endophytic fungus Aspergillus sp. Y16. Bioresource Technol., 102: 8179-8184. PMID: 21733681

Dilorio, P., P. Ballerini, U. Traversa, F. Nicoletti and I. D'Alimonte et al., 2004. The antiapoptotic effect of guanosine is mediated by the activation of the PI 3kinase/AKT/PKB pathway in cultured rat astrocytes. Glia, 46: 356-368. DOI: 10.1002/glia.20002

Helmink, B.A. and J.A. Friesen, 2004. Characterization of a lipid activated CTP: Phosphocholine cytidylyltransferase from Drosophila melanogaster. Biochim Biophys Acta, 1683: 78-88. PMID: 15238222

Hu, H.H., Z.Y. Zhang, Z.F. Lei, Y.N. Yang and N. Sugiura, 2009. Comparative study of antioxidant activity and antiproliferative effect of hot water and ethanol extracts from the mushroom Inonotus obliquus. J. Biosci. Bioeng., 107: 42-48. PMID: 19147108

Hung, W.T., S.H. Wang, C.H. Chen and W.B. Yang, 2008. Structure determination of $\beta$-glucans from Ganoderma lucidum with Matrix-Assisted Laser Desorption/Ionization (MALDI) mass spectrometry. Molecules, 13: 1538-1550.

DOI: $10.3390 /$ molecules 13081538

Jiang, Y.Z. and P. Patrice, 2006. Raw material enzymatic activity determination: A specific case for validation and comparison of analytical methods--the example of Superoxide Dismutase (SOD). J. Pharmaceut. Biomed., 40: 1143-1148. PMID: 16280223

Klimczak, I., M. Malecka, M. Szlachta and A. Gliszczynska-Swiglo, 2007. Effect of storage on the content of polyphenols, vitamin $\mathrm{C}$ and the antioxidant activity of orange juices. J Food Compos. Anal., 20: 313-332

Kozarski, M., A. Klaus, M. Niks`ic, M.M. Vrvic and N. Todorovic et al., 2012. Antioxidative activities and chemical characterization of polysaccharide extracts from the widely used mushrooms Ganoderma applanatum, Ganoderma lucidum, Lentinus edodes and Trametes versicolor. J. Food Compos. Anal., 26: 144-153. DOI: 10.1016/j.jfca.2012.02.004
Kregel, K.C. and H.J. Zhang, 2007. An integrated view of oxidative stress in aging: Basic mechanisms, functional effects and pathological considerations. Am. J. Physiol. I., 292: 18-36. PMID: 16917020

Leung, P.H., S. Zhao, K.P. Ho and J.Y. Wu, 2009. Chemical properties and antioxidant activity of exopolysaccharides from mycelial culture of Cordyceps sinensis fungus Cs-HK1. Food Chem., 114: 1251-1256. DOI: 10.1016/j.foodchem.2008.10.081

Li, S.H., L.B. Wang, C.F. Song, X.S. Hu and H.Y. Sun et al., 2014. Utilization of soybean curd residue for polysaccharides by Wolfiporia extensa (Peck) Ginns and the antioxidant activities in vitro. J. Taiwan Inst. Chem. E., 45: 6-11. DOI: $10.1016 /$ j.jtice.2013.05.019

Li, S.P., F.Q. Yang and K.W.K. Tsim, 2006. Quality control of Cordyceps sinensis, a valued traditional Chinese medicine. J. Pharmaceut. Biomed., 41: 1571-1584. DOI: 10.1016/j.jpba.2006.01.046

Li, H.X., T. Qiu, G.D. Hang and Y.S. Cao, 2010. Production of gamma-aminobutyric acid by Lactobacillus brevis NCL912 using fed-batch fermentation. Microb. Cell Fact. PMID: 21070676

Li, Y.T., S.L. Meng, L.B. Wang and Z.Y. Zhang, 2015. Optimum fermentation condition of soybean curd residue and rice bran by Preussia aemulans using solid-state fermentation method. Int. J. Biol., 7: 66-74. DOI: 10.5539/ijb.v7n3p66

Liu, W., H.Y. Wang, X.B. Pang, W.B. Yao and X. Gao, 2010. Characterization and antioxidant activity of two low-molecular-weight polysaccharides purified from the fruiting bodies of Ganoderma lucidum. Int. J. Biol. Macromol., 46: 451-457.

DOI: $10.1016 /$ j.ijbiomac.2010.02.006

Masuko, T., A. Minami, N. Iwasaki, T. Majima and S. Nishimaru et al., 2005. Carbohydrate analysis by a phenol-sulfuric acid method in microplate format. Anal. Biochem., 339: 69-72. DOI: $10.1016 /$ j.ab.2004.12.001

Meng, L.Z., B.Q. Lin, B. Wang, K. Feng and D.J. Hu et al., 2013. Mycelia extracts of fungal strains isolated from Cordyceps sinensis differently enhance the function of RAW 264.7 macrophages. J. Ethnopharmacol., 148: 818-825. DOI: $10.1016 /$ j.jep.2013.05.017

Mizumoto, S., M. Hirai and M. Shoda, 2006. Production of lipopeptide antibiotic iturin A using soybean curd residue cultivated with Bacillus subtilis in solid-state fermentation. Applied. Microbiol. Biot., 72: 869-875. DOI: 10.1007/s00253-006-0389-3

Mohsen, M.S.A., M.A. Youssri and F.R. Mohamed, 2009. Chemical characteristics and antioxidant activity of exopolysaccharide fractions from Microbacterium terregens. Carbohyd. Polym., 77: 563-567. DOI: 10.1016/j.carbpol.2009.01.037 
Moradali, M., H. Mostafavi, S. Ghods and G. Hedjaroude, 2007. Immunomodulating and anticancer agents in the realm of macromycetes fungi (macrofungi). Int. Immunopharmacol., 7: 701-724.

DOI: $10.1016 /$ j.intimp.2007.01.008

Nakajima, Y., Y. Sato and T. Konishi, 2007. Antioxidant small phenolic ingredients in Inonotus obliquus (persoon) Pilat (Chaga). Chem. Pharm. Bull., 55: 1222-1226. DOI: $10.1248 / \mathrm{cpb} .55 .1222$

Pan, D.D. and X.M. Mei, 2010. Antioxidant activity of an exopolysaccharide purified from Lactococcus lactis subsp. lactis 12. Carbohyd. Polym., 80: 908-914. DOI: 10.1016/j.carbpol.2010.01.005

Paterson, R.R., 2008. Cordyceps-A traditional Chinese medicine and another fungal therapeutic biofactory. Phytochemistry, 69: 1469-1495.

DOI: 10.1016/j.phytochem.2008.01.027

Puttaraju, N.G., S.U. Venkateshaiah, S.M. Dharmesh, S.M.N. Urs and R. Somasundaram, 2006. Antioxidant activity of indigenous edible mushrooms. J. Agr. Food Chem., 54: 9764-9772. DOI: $10.1021 / \mathrm{jf06} 15707$

Schepetkin, I.A. and M.T. Quinn, 2006. Botanical polysaccharides: Macrophage immunomodulation and therapeutic potential. Int. Immunopharmacol., 6: 317-333. DOI: 10.1016/j.intimp.2005.10.005

Shi, M., Y.N. Yang, D. Guan, Y. Zhang and Z.Y. Zhang, 2012. Bioactivity of the crude polysaccharides from fermented soybean curd residue by Flammulina velutipes. Carbohyd. Polym., 89: 1268-1276. DOI: 10.1016/j.carbpol.2012.04.047

Shi, M., Y.N. Yang, D. Guan, Y.P. Wang and Z.Y. Zhang, 2013. Evaluation of solid-state fermentation by ganoderma lucidum using soybean curd residue. Food Bioprocess Tech., 6: 1856-1867. DOI: $10.1007 /$ s1 1947-012-0857-y

Shi, M., Y.N. Yang, Y.T. Li, Y.P. Wang and Z.Y. Zhang, 2011. Optimum condition of ecologic feed fermentation by pleurotus ostreatus using soybean curd residue as raw materials. Int. J. Biol., 3: 1-12. DOI: $10.5539 /$ ijb.v3n4p2

Song, G.L. and Q.Z. Du, 2012. Structure characterization and antitumor activity of an $\alpha \beta$-glucan polysaccharide from Auricularia polytricha. Food Res. Int., 45: 381-387.

DOI: 10.1016/j.foodres.2011.10.035

Squadriato, G.L. and W.A Pryor, 1998. Oxidative chemistry of nitric oxide: The roles of superoxide, peroxynitrite and carbon dioxide. Free Radical Biol. Med., 25: 392-403.

DOI: $10.1016 / \mathrm{S} 0891-5849(98) 00095-1$
Surel, O. and B. Couplet, 2005. Influence of the dehydration process on active compounds of okara during its fractionation. J. Sci. Food Agric., 85: 1343-1349. DOI: 10.1002/jsfa.2097

Wang, J.Q., L.J. Kan, S.P. Nie, H.H. Chen and S.W. Cui et al., 2015. A comparison of chemical composition, bioactive components and antioxidant activity of natural and cultured Cordyceps sinensis. LWT-Food Sci. Technol., 63: 2-7.

Waris, G. and H. Ahsan, 2006. Reactive oxygen species: Role in the development of cancer and various chronic conditions. J. Carcinogenesis, 5: 1-8. DOI: $10.1186 / 1477-3163-5-14$

Wong, C.G., T. Bottiglieri and O.C. Snead, 2003. GABA, gamma-hydroxybutyric acid and neurological disease. Ann. Neurol., 54: S3-12. DOI: $10.1002 /$ ana. 10696

$\mathrm{Wu}$, X.J. and C. Hansen, 2008. Antioxidant capacity, phenol content and polysaccharide content of Lentinus edodes grown in whey permeate-based submerged culture. J. Food Sci., 73: 1-8. DOI: $10.1111 /$ j.1750-3841.2007.00595.x

Yamamoto, T., H. Koyama, M. Kurajoh, T. Shoji and Z. Tsutsumi et al., 2011. Biochemistry of uridine in plasma. Clin. Chim. Acta., 412: 1712-1724. DOI: $10.1016 /$ j.cca.2011.06.006

Yamamoto, T., Y. Moriwaki, J. Cheng, S. Takahashi and Z. Tsutsumi et al., 2002. Effect of inosine on the plasma concentration of uridine and purine bases. Metabolism, 51: 438-442.

DOI: $10.1053 /$ meta.2002.31322

Yan, J.K., L. Li, Z.M. Wang and J.Y. Wu, 2010. Structural elucidation of an exopolysaccharide from mycelial fermentation of a Tolypocladium $s p$. fungus isolated from wild Cordyceps sinensis. Carbohyd. Polym., 79: 125-130. DOI: $10.1016 /$ j.carbpol.2009.07.047

Yan, J.K., W.Q. Wang and J.Y. Wu, 2014. Recent advances in Cordyceps sinensis polysaccharides: Mycelial fermentation, isolation, structure and bioactivities: A review. J. Functional Foods, 6: 33-47. DOI: 10.1016/j.jff.2013.11.024

Zhang, Y.J., B.D. Sun, S. Zhang, M. Wang and X.Z. Liu et al., 2010. Mycobiotal investigation of natural Ophiocordyceps sinensis based on culturedependent investigation. Mycosystema, 29: 518-527. 